\title{
Analyzing a Piece of Teaching Through the Lens of The ABCs of How We Learn: 26 Scientifically Proven Approaches, How They Work and When To Use Them
}

Excelsior: Leadership in

Teaching and Learning 2019, Vol. 12(1) 37-52

(C) The Author 2019 CC-BY 4.0 International Reprints and permissions: surface.syr.edu/excelsior https://doi.org/10.14305/jn.1

9440413.2018.12.1.02 nyacte.org

\section{Kimberly Alexander ${ }^{1}$ and Paul Vermette ${ }^{2}$}

\begin{abstract}
For the continuing development of quality instructional practices, educators must have access to the findings of research and be in a position to explore applications of those findings. We think we may have found such a resource: A 2016 book titled The ABCs of How We Learm. 26 Scientifically proven approaches, how they work, and when to use themby Schwartz, Tsang, and Blair is a concise, insightful, and applicable set of 26 short articles that explain key learning factors, provide examples, and identify the supporting scholarship. In this article, a first-year middle school science teacher and a veteran teacher educator offer teacher educators and professional developers an overview of the 26 factors as they work in a middle school science classroom and an example of how to effectively utilize this text in teacher education programs via vignette creations and analyses.
\end{abstract}

\section{Keywords}

teacher education, clinical practice, clinical educator, professional development, teacher perceptions

In 2016, Schwartz, Tsang, and Blair published The ABC's of How We Learn: 26 Scientifically proven approaches, how they work, and when to use them and may have offered a way to revolutionize approaches to teacher lesson planning and reflection. The strategies in this book represent a compendium of educational research findings and, when combined, seamlessly describe effective

\footnotetext{
${ }^{1}$ Lewiston-Porter Central School District

2 Niagara University

Corresponding Author:

Kimberly Alexander, Lewiston-Porter Middle School, 4061 Creek Road, Youngstown, NY 14174

Email: kalexander@lew-port.com
} 
teaching practices. In this article, we analyze how the various strategies can be woven together. To accomplish this, we have analyzed a piece of teaching through the lens of the ABCs. The lesson is described as a timestamp narrative to give readers a clearer picture of the activities taking place but the formal lesson plan also follows. We ask readers to identify elements of the timestamp lesson that they believe are effective teaching strategies. We have found evidence of 14 of the 26 strategies esteemed by Schwartz, Tsang, and Blair in this lesson. Please note that this lesson was adapted from the Modeling Curriculum (American Modeling Teacher Association, 2014). In particular, we have adapted the Discovering Plate Boundaries lesson found under Middle School Science, Grade 7, Unit 4.3, Activity 3. Alexander frequently pulls from the Modeling Curriculum (American Modeling Teacher Association, 2014) in her classroom as she feels that the lessons not only reflect the strategies from Schwartz, Tsang, and Blair but also dovetail with the New York State Science Learning Standards and the Next Generation Science Standards. After our analysis of the lesson, we offer a breakdown of the remaining 12 strategies to provide readers with a complete overview of the book.

We propose that our article can lessen the gap between teacher practice (both pre-service and inservice) and research. We see this article as a chance to enlighten, to offer practical research-supported applications, and to spark further discussion in teacher education classrooms. We hope that the inclusion of the time stamp lesson plan, as well as the full lesson plan, empower teacher educators, preservice teachers, and in-service teachers to analyze the lesson in multiple ways and encourage all to compare their own analyses to ours. Please note that for each factor, Schwartz, Tsang, and Blair cite multiple, relevant research studies that could be further analyzed by in-service and pre-service teachers.

\section{Time Stamp Version of the Lesson: Discovering Plate Boundaries}

*Please note that the content of this lesson was adapted from the Modeling Curriculum: (CAmerican Modeling Teacher Association 2014,MSS Gr 7 U 4.3 Act 3: Discovering Plate Boundaries

8:38 - Miss Alexander greets students at the door as the bell rings.

8:39 - Miss Alexander welcomes the class and informs them that they will be completing a "jigsaw" style activity today. She explains that this means they will work in two different groups and that unlike their normal base groups, today's groups will be randomly assigned. As she explains this, students draw a colored index card from her. Each card has a type of scientist and a letter listed.

8:41 - Miss Alexander reminds the class that they've been discussing Wegener's theory of continental drift and poses the question, "Is it only the continents that move?" as she passes out the activity sheets. Juan posits a confident yes to this, while Julia simultaneously and boldly answers with a no. Miss Alexander lets students know that disagreement at this point was expected and the class will use today's activity to come to consensus on this opening question. She then describes the goal of the first grouping of the jigsaw. Students will work with a group of similar scientists to analyze a map. For the second half of class they will need to explain their map to others who have not seen it, so they will need to become an expert on the map. In the first group, they will work with similar scientists to answer some scaffolding questions. She reviews the role of each scientist with the students, explaining that seismologists study earthquakes, volcanologists study volcanoes, and geochronologists study the age of the sea floor. After explaining where each group is to meet, she asks students to find their first group.

8:44 - Miss Alexander circulates the room helping the groups of similar scientists analyze their maps 
and answer their scaffolding questions. She helps students interpret the orientation of their map (for most of the maps North America is on the right which is unfamiliar to students). She coaches groups on their affective skills as needed, requiring all members to be respectful participants. At the seismologist group, students are discussing the map's color coding and looking for patterns in data. At the volcanologist group, students are confused by the map's orientation. They have noticed that the continents are labeled but cannot identify the oceans. Johnny notes that "most of the volcanoes occur in this ocean." Miss Alexander prompts "Great observation Johnny. Which ocean is this?" Johnny's first answer is "Atlantic" because he is used to seeing the Atlantic Ocean in the center of the map, but his teammate Aisha notices this can't be correct and interjects, "It can't be the Atlantic because it's touching California here." Johnny corrects himself adding, "It must be the Pacific Ocean." Miss Alexander encourages the group to add the ocean name to their notes. The geochronologists are working to identify patterns in their map having already noted the color-coded key. Miss Alexander gives the class a two-minute warning to finish the first part of the activity.

8:55 - Miss Alexander pauses the groups and informs them that they will be moving into their second groupings. They will now work with a group of diverse scientists to share what they have learned and draw connections between the disciplines. She tells students that this is typical of the work of real scientists. Sometimes they work with people in their field and sometimes they collaborate with people in other fields. She reminds students of where the new groupings will meet and asks them to regroup themselves.

8:57 - Miss Alexander circulates the room as students share their findings with each other to answer the second set of scaffolding questions. One of the boys in Group A, Tommy, doesn't appear to be contributing. His groupmate, Malia, is asking Tommy to explain his map. "What did you guys put for question 5? Your map is confusing." Tommy doesn't respond. Miss Alexander interjects, "Tommy, look at Malia's map. It's in a different orientation than yours and that might cause confusion in your group. Malia's map shows North America on the left. Where is North America on your map?" Tommy points to North American on his map and Miss Alexander reminds him, "Correct. Don't forget Tommy that you're the only one who has had time to analyze the earthquake map. Your role is to be the earthquake expert because your team is counting on you to have the earthquake data." When it seems that Tommy is willing to participate Miss Alexander steps away. Group $\mathrm{C}$ is struggling to draw connections between all three maps. Sheng asks her "Miss Alexander, these two maps are very similar but we don't see how the third fits in." Miss Alexander responds, "That is a great observation and should go on your whiteboard. It seems that one of these things is not like the others. Let's start with the two maps you feel comfortable with. Why do you think the earthquake map is so similar to the volcano map?" Sheng replies "because earthquakes and volcanoes happen in the same spots." Miss Alexander prompts a deeper explanation, "Yes and why do you think that is the case? Think about what this suggests about the crust at these locations." Before Sheng can ask another question, she starts to drift away. Many students, like Sheng, are still working on their critical thinking skills and want the teacher to answer the question for them. Miss Alexander habitually gives students a follow up question, and as she does now says "Think about this for a minute and I'll be back." After swinging back by Group A to ensure Tommy is still participating she heads to Group D where she notices some students have solved the puzzle pieces. They have concluded that where the ocean floor is youngest new rock is forming from lava. They have recorded their idea about a "crack" in the ocean floor where the magma rises up. Miss Alexander prompts this 
group to get their ideas on the whiteboard without indicating whether their ideas are correct. This frustrates some of the higher achieving students who are uncomfortable making mistakes, but this is a goal of whiteboarding. Miss Alexander wants the students to see mistakes as a part of learning. She circles back to Group $\mathrm{C}$ and notices that they have developed an answer to her last question, suggesting that the crust is "weaker" at the volcano and earthquake locations. They are still struggling with connecting the sea floor map to their ideas. Miss Alexander suggests "Keep treating the sea floor map separately for now. What can you tell me about the crust at different points on this map? Work on this first and don't worry if you can't connect them all on the whiteboard." Miss Alexander then reminds all students that their answers to the last two questions need to be on a whiteboard. She reminds groups where to post their whiteboards when completed. With the two-minute warning, she says, "Two minutes to get something on the whiteboard. Remember boards do not have to be correct but they cannot be blank."

9:07 - Miss Alexander calls the class together for a brief circle whiteboarding session. All groups have displayed their boards around the room. She first asks students to note similarities and differences between the boards. Julia notices "three groups said the earthquake map is similar to the volcano map." Miss Alexander asks why students think this is the case and intentionally calls on Bella from Group $\mathrm{C}$ who says "we think the crust is weaker at those places so more earthquakes and volcanoes occur there." Miss Alexander then helps the groups to tie in the sea floor map asking where "young" sea floor comes from. Jamal says "The sea floor is made of rocks, so new floor is made when lava comes up to the surface and cools." Miss Alexander asks various groups to share their ideas of what is happening to the crust at "weak spots" and the "new sea floor spots" and draws out from students their idea that the crust is "broken." She then asks students what they could call the "pieces" of the broken crust, to which a few recall the vocabulary word "plates" from last year. At this point, Jason realizes they are now learning about plate tectonics and shouts out "hey, last year we had a map showing where all the plates are." Miss Alexander asks Jason what they called the "cracks" between the plates on that map and Jason correctly recalls the term "boundary." Miss Alexander congratulates the teams on discovering the existence and location of the plate boundaries. She tells them that this collaborative activity is very similar to how the actual discovery of plate tectonics was made, which led to the creation of the Plate Tectonics Map they studied last year. She also circles back to the original question and students confirm that it is not only the continents that move but the oceans too as the plates below the continents and oceans are doing the moving.

9:17 - As class wraps up, she reiterates that the class has discovered the map of plate boundaries and she begins to foreshadow the next question: If new sea floor is produced at the ocean boundaries, why is the Earth not getting bigger? A few groups have stumbled on this idea already and one believes they have a solution. She lets them know that they will answer this question tomorrow. She thanks them for their great work and wishes them a great day as the bell rings.

\section{Breaking Down this Lesson According to the ABC's}

We believe this lesson can be connected to the following strategies from the $A B C$ 's of How We Learn: 26 Scientifically proven approaches, how they work, and when to use them. We acknowledge that some of the connections are stronger than others, but a case can be made that this lesson addresses 14 of the 26 strategies in this text. For each strategy or letter, Alexander analyzes the lesson first, from the 
perspective of the relatively new teacher, and then Vermette offers an additional take from a veteran observer's perspective. Please note that when used in an actual learning activity, readers could do their own analyses first before reading our insights.

$B$ is for Belonging- Belonging is established within a classroom's culture and cannot be built in a single lesson but I believe that it is clear that students in this class feel a sense of belonging because of their ability to quickly and respectfully move into new groups at two separate points in this lesson. The existence of base groups as well as the mixing of groupings used in a jigsaw encourage a sense of belonging among students. This is evident in the role that all students play in the jigsaw which Miss Alexander uses to motivate Tommy in the second grouping. This sense of belonging is further encouraged by the greeting offered to students at the door as they enter and the teacher's language of welcoming students and praising their efforts.

Vermette's Take: Moreover, there were no indications of rejection by any students to any other students. There was no evidence of groans or ugly faces as the students interacted. This teacher clearly wants all students to feel that they are part of the community and that they can trust each other. This sense of belonging (Glasser, 1999) will also help reticent students to take chances and offer ideas that they otherwise may fear to share.

$E$ is for Elaboration-Elaboration is used when students connect new learning to prior knowledge. In the first part of class they build on their prior knowledge of map skills (Chapter $\mathrm{K}$ is for Knowledge). It is clear that students have background knowledge on the continents and oceans and we see them using this background knowledge to interpret maps in new orientations. Additionally, the students have some background in plate tectonics but they must use this to explore the process of the discovery of plates, rather than simply recall facts. For example, they are asked, "What do you know about earthquakes and what does that suggest about the crust at this point on your map?" This discovery of the process behind the science also encourages them to use elaboration to build on prior knowledge.

Vermette's Take: Constructivism holds that new knowledge must be built as an extension of old knowledge (prior knowledge and prior experience). By tapping back into both one-year old experiences and ones from the first ten minutes, her students are seamlessly restructuring their schema and creating their own new conceptual understandings.

$F$ is for Feedback- Feedback is provided to groups as the teacher circulates through the groups and during the circle whiteboarding session as the teacher facilitates the discussion.

Vermette's Take: This teacher's feedback is timely because it is given when learning is happening. It is clear and understandable and can be used by students, whether it changes their ideas or whether it sparks a re-examination of their current thinking. Drawing on Hattie and Timperley (2007) good feedback should be timely, understandable, non-threatening, and useful for revision, just as it is used here.

$G$ is for Generation- Generation is used when students retrieve a memory given partial clues. Students have learned about plate tectonics in previous grades but they need to rediscover this memory through the activity. This occurs during the circle whiteboarding as Miss Alexander asks what terminology was used to describe "cracks" in the crust in $6^{\text {th }}$ grade.

Vermette's Take: It also happens to other students as they do similar things to Jason. "Deep thinking," which is demanded by this activity and reinforced by the student collaboration forces learners to build off of partial clues and partial understandings. Like elaboration (above) generation utilizes the brain's tendency to make sense of information and to seek coherence and pattern. Such brain activity can cause misconceptions, but if so, they could be "unlearned" in the same fashion. As such, mistakes are raw material for future thinking. 
J is for Just-in-time Telling-Just-in-time telling describes a constructivist teaching strategy that follows the two-step lesson planning model (Flynn, Mesibov, Vermette, \& Smith, 2004) in which students first explore a problem before discovering a solution. The "answer" to the essential question of this lesson (what and where are the plate boundaries) is divulged in the last few minutes of this lesson and only afterstudents first pose the question (notice the problem), "Why and where is the crust broken?" This lesson closely follows the two-step model. The opening is the distribution of the colored cards and the prompt, "Is it only the continents that move?" The exploratory phase includes the first jigsaw group where students work with similar scientists. The discovery phase includes the second jigsaw group as students grapple with the connections between the maps (and some make the discovery of the "cracks" in the crust). The closing serves to ensure all students have made the important discovery of the plate boundaries and takes the form of the circle whiteboarding session.

Vermette's Take: Perhaps our favorite of the 26 "letters" in the book, J (just in time telling) is a very difficult concept for teachers to learn to use because there is no real way to accurately predict the timing. If the "answer" (we prefer the word "resolution") comes too soon, student thinking is short-circuited and one is playing the memory game of school: I can state it but I don't really get it. If it comes too late, the student may have lost focus or become distracted. Timing of the feedback, called "telling," is chiefly an art that is mastered largely by careful planning and knowing the students well. Clearly Miss Alexander does both. (Please note that in most models of explicit teaching, the answer is given at the beginning of the lesson, before any curiosity is aroused, before any applications of prior [background] knowledge is generated, before students form any of their own questions, and before they even start to care. How awful such thinkingfree classes must be. Note that D is for deliberate practice and Schwartz, Tsang, and Blair [2016] strongly suggest that deliberate practice is for experts, not novices. Early learning must be shaped by tentative, exploratory thinking, and careful examination of the results of that thinking.)

$L$ is for Listening and Sharing-Students must listen and share ideas in both pieces of the jigsaw as well as during the circle whiteboarding discussion. This behavior is encouraged because each student is the expert on his/her map in the second grouping. Tommy is specifically encouraged to listen and share in Group A as Miss Alexander reminds him of his role in the jigsaw.

Vermette's Take: Implied throughout the entire lesson is the expectation that students will collaborate like real scientists. They offer ideas, they challenge ideas (NOT other people), and they back up their suggestions with logic and evidence. They are also expected to communicate in a respectful way. Like B above, and N below, L\&S are Social-Emotional Skills that high school graduates are expected to be good at as they enter the adult world of business, family, and citizenship.

$N$ is for Norms - Like belonging, norms are not established in a single class period, but it is clear that students understand a set of norms based on their actions in today's activity. They are able to quickly and respectfully move around the classroom, indicating they know what is expected of them in transitions to new groups. Furthermore, a set of whiteboarding norms must be known as students quickly build boards and seem to know how to share and discuss these with little prompting. The circle whiteboarding discussion in this lesson only spans about ten minutes of time, so it is clear that it is not the first-time students have used whiteboarding strategies like this.

Vermette's Take: As you re-read this passage, look for places where Miss Alexander is reinforcing her expectations/norms: there are many. In the passage, readers do not see her 
expectations posted, however, they are listed below and are visible on three walls of her classroom.

Note from Alexander: My expectations are broken into three categories. I have three general classroom expectations that replace typical "classroom rules." I have eleven whiteboarding norms that dictate protocol for whiteboarding sessions and discussions. Finally, I display the 16 Habits of Mind (Costa \& Kallick, 2000) in my classroom as I use this framework to incorporate social and emotional learning through dual objective lessons (Vermette \& Kline 2017).

1) General Classroom Expectations:

1. Expectation 1: We will be respectful. Why? We will create a safe space where everyone can learn.

2. Expectation 2: We will be prepared. Why? We will learn responsibility.

3. Expectation 3: We will be inquisitive. Why? We will learn to think like true scientists.

2) Whiteboard Norms (Buffalo State, 2016)

1. Take turns.

2. Disagree with ideas, not people.

3. Be respectful.

4. You have the right to ask anyone in your group for help.

5. You have the duty to give help to anyone who asks.

6. No one is done until everyone is done.

7. Remember to play your role.

8. Say your "becauses."

9. Helping is not the same as giving answers.

10. Confusion is a part of learning.

11. Listen to others' ideas

3) 16 Habits of Mind (Costa \& Kallick, 2000)

1. Persisting

2. Managing impulsivity

3. Listening with understanding and empathy

4. Thinking flexibly

5. Thinking about your thinking (metacognition)

6. Striving for accuracy and precision

7. Questioning and problem posing

8. Applying past knowledge to new situations

9. Thinking and communicating with clarity and precision

10. Gather data through all senses

11. Creating, imagining, and innovating

12. Responding with wonderment and awe

13. Taking responsible risks

14. Finding humor

15. Thinking interdependently

16. Remaining open to continuous learning 
$P$ is for Participation- Each student has a vital role in this jigsaw as he/she will be the only expert on his/her map in the second grouping. This increases participation as does the use of just-in-time telling. Students are invested in the circle whiteboarding discussion because they want answers to the questions they have posed and struggled with (such as "How does the sea floor map fit in?" and "What would it mean if crust is broken here?")

Vermette's Take: Remember, "If you can teach the lesson without any students there, DONOT BOTHER. "Of course, this annoys many of his University brethren but it is sound advice for $P$ 12 schooling. Every student matters in this lesson; every student's idea is part of the plan. The teacher has carefully planned her questions and activities, and she is ready to handle anticipated and unanticipated responses. This is a highly skilled teacher at work.

$Q$ is for Question-driven - The lesson is driven by questions from both teacher and students. The lesson aims to have students develop and answer the essential question (what and where are the plate boundaries?). The opening question (is it only the continents that move?) is carefully used to point toward this essential question and the scaffolding questions (taken from the activity worksheet, American Modeling Teachers Association, 2014) are key to helping students develop this. Therefore, the questions posed by the teacher and recorded on the worksheet are well developed to guide inquiry. Additionally, the activity encourages students to pose their own questions to one another and helps them to develop answers to these.

Vermette's Take: Good questions come from intentional teacher planning, teacher "reading" the situation and from students as they think and feel and ask. Constructivist educators think that effective lessons are driven by student responses (Brooks \& Brooks, 1993; Ladson-Billings, 2009). Miss Alexander's questions all seek to make students think for themselves, connect pieces that they are struggling to make sense of and to re-focus their efforts. One other point, worth sharing, is that all tasks and learning activities are really "questions" at their core (Vermette \& Alexander, 2019) because they seek to get students to negotiate their own meanings (Vermette, 2009). If you re-examine this lesson, you will find an enormous number of thought-provoking questions AND tasks. Some important ones that we identify include:

1. The opening question, "Is it only the continents that move?" is essential as it drives the lesson, serves to undo a common misconception (see Ubelow), and propels the course along the trajectory of the science in the same way it was originally discovered.

2. The map analysis task is crucial as it begs the questions "What?" and "So What?" as students interpret what they are looking at and why it is significant.

3. The second jigsaw component is also vital as it asks, "What do the maps have in common?" since this represents higher order thinking and accurately represents interdisciplinary thinking and collaboration practiced by real scientists.

$S$ is for Self-Explanation- The scaffolding questions encourage students to build explanations to the maps' connections. Students must share their own explanations with each other as they work together to analyze each map.

Vermette's Take: Generally speaking, self-explanation can lead to misunderstandings and misconceptions, but with fellow students surrounding each other and Miss Alexander "working the room"so effectively, this is probably not the problem that it can be when students are working silently alone, in class or at home.

$T$ is for Teaching - The teacher truly has the role of facilitator in today's activity. Students teach each other their maps in the second grouping and the teacher simply guides discussion. Furthermore, it is the goal of circle whiteboarding to have students lead discussion. It seems that Miss Alexander is well on her 
way to this form of discussion, but has room to improve, as she could develop some additional prompts to students in this discussion.

Vermette's Take: Linked in this lesson to S above, the students become the teacher of others, and develop the best possible understanding. We have known that teaching is the best thing for learning since the 1980s but it is often difficult to get teachers to take advantage of this principle.

$U$ is for Undoing - This lesson addresses the misconception that only the continents move. Students are working through the history of science to discover the flaws in Wegener's theory and to build a subsequent improved theory (the theory of plate tectonics), just as the original scientists who discovered plate boundaries did.

Vermette's Take: Intuitive theories are often wrong and misconceptions abound in all disciplines, but they are deadly in science. Undoing misconceptions is very important work and inviting them into public discussion, so they can be re-examined, is again a skillful act of instruction.

$X$ is for eXcitement - As simple as it sounds the mysterious colored index cards incite excitement as does the potential for new random groupings in this seventh-grade class.

Vermette's Take: We rarely see students "too motivated" to get work done, so we can ignore the right-hand side of the Yerkes-Dodson law for a second. However, getting students enthused, curious, speculating and paying close attention (Goleman, 2013) is crucial to effective teaching both in a single lesson, and when it appears regularly, over time. Students want to be interested, they want to be engaged and they want to feel competent. All of these factors are present in this lesson.

$Y$ is for Yes, / can! - As with any Modeling activity (American Modeling Teachers Association, 2014) this lesson is truly an effort in frustration management. Students struggle at several points of this lesson and the teacher encourages them to persist using a growth mindset. Sheng's ability to persist in the task even after Miss Alexander refuses to answer all of his questions suggests that students are accustomed to having to persist and try to solve problems on their own in this classroom. Furthermore, Miss Alexander's expectation that the whiteboards "do not have to be correct but cannot be blank" illustrates that she values a growth mindset (Dweck, 2008). She also acknowledges that her highachieving students are still working toward this growth mindset as several of them are not yet comfortable making mistakes. Miss Alexander's goal for the class to see mistakes as a part of learning further develops the value she wants her students to place on a growth mindset.

Vermette's Take: Obviously, today we know that both GRIT (Duckworth, 2016) and GROWTHMINDSET (Dweck, 2008) are central to student achievement and the carefully placed struggles that students experienced were natural, challenging and sparked thinking. Students must expect to have to "work" in Miss Alexander's class but actually anticipate that if they do work, they'll succeed. Notice how many times they had to "go back and struggle again" to complete their task and develop understanding.

\section{Extension}

We see this article, and the Schwartz, Tsang, and Blair (2016) book The ABC's of How We Learn: 26 scientifically-proven approaches, how they work, and when to use them, as having value for teacher education programs and professional development. Simply put, the book is a really powerful resource. However, the Miss Alexander lesson didn't seem to use all 26 of the sections of the book (all of the 
"letters"), so we thought we'd include a little bit about each of the others so the reader can get a better flavor of the whole work. We hope that you decide to buy it, read it, investigate the research base they offer as evidence, and apply it to teacher thinking, teacher planning, and student learning.

In closing, let's briefly mention the 12 factors that we did not "see" in use during Miss Alexander's lesson. The list includes these sections/letters: A, C, D, H, I, K, M, O, R, V, W, and Z We wish to take each of these and give a short explanation.

$A \& C: A$ is for analogies and $C$ is for contrasting cases - When students actively identify similarities and/or distinguish between cases, they find important attributes that help them clarify their developing conceptions. These processes are central to concept development (Bruner, 1956; Frayer, Frederick, \& Klausmeier, 1969). We believe that all teaching incorporates these two strategies, for to truly understand a new concept you must understand how it fits into your existing schema (draw an analogy) and then determine how it is distinct from your prior knowledge (see it as a contrasting case).

$D$ is for Deliberate Practice - Deliberate practice (Ericsson, Krampe, \& Tesch-Römer, 1993) is the intense, exhausting, detail focused, repetitive practice that is crucial in developing expertise. As mentioned earlier, it is inviting for teachers to ask students to do 10, 20, or 30 sample problems so they try to "automatize" a procedure without conceptual understanding. However, Schwartz, Tsang, and Blair (2016) point out that such repetitive practice is best for those who have existing expertise and is far less useful for novice learners such as those seventh graders we have shown you. Miss Alexander is wise to cut out the time-wasting simple regurgitative memorization that is still seen in some schooling.

$H$ and l: H is for Hands-on Learning and I is for Imaginative Play -Schwartz, Tsang, and Blair (2016) describe these two factors as mostly applicable to elementary level activities. There is "playing with ideas" in this lesson which is "minds-on" but it is not the role-playing or physical manipulation that is indicated in these two sections of the book.

$K$ is for knowledge-Schwartz, Tsang, and Blair (2016) acknowledge this is a "different kind of chapter." They pull back from their parade of research-based evidence for increasing learning to fully philosophize about the role that (prior) knowledge plays in the learning of (new) knowledge. Miss Alexander knows this body of work and adjusts the lesson to have students call up prior knowledge, play with new ideas, connect new ideas to available ideas heard in the small groups, and move toward discovering for themselves. A two-step model for lesson creation and classroom practice (Flynn, Mesibov, Vermette \& Smith, 2004) has been designed to structure this process (first explore, then discover) and this chapter provides strong evidence for its wisdom.

$M$ is for making - This chapter is an interesting addition in this time of the "maker movement." While it may not be evident in this particular lesson, Miss Alexander can utilize "making" in other lessons that call for active learning and product creation. In fact, prior to this lesson, students had to re-create a map of Pangaea using fossil evidence to align continents properly. This previous lesson helped to establish the essential question of whether it is only the continents that move. The maker movement has arisen at the perfect time in light of the new three-dimensional science standards. As students utilize the new science and engineering practices, they should be encouraged to design and build models and solutions within the classroom. The maker movement combines the elements of digital tools, community infrastructure, and a maker mindset to make learning environments more engaging and productive (Martin, 2015). Another noteworthy application of the strategies in this chapter can be found in the use of project-based learning (PBL). PBL encourages students to produce a physical product that provides a solution to an authentic problem. Furthermore, PBL requires the use of cooperative learning groups and is perfectly suited for the use of dual objective teaching (Vermette \& Kline, 2017). Through the dual 
objective, teachers simultaneously teach cognitive and affective skills to their cooperative learning groups and therefore the strategy of PBL also dovetails quite nicely with all of the social and emotional learning (SEL) chapters of Schwartz, Tsang, and Blair (2016) as well. These SEL chapters include B is for Belonging, $\mathrm{L}$ is for Listening and Sharing, $\mathrm{N}$ is for Norms, $\mathrm{P}$ is for Participation, $\mathrm{X}$ is for eXcitement, and $\mathrm{Y}$ is for Yes, I can.

$O$ is for observation - This factor is generally perceived as a lesson in which a formal, teacher-led, demonstration occurs and this certainly is common in science class. Schwartz, Tsang, and Blair (2016) place emphasis on identifying the steps of the demonstration so students can tease out the important components. Miss Alexander did not see any value in taking time out to show students what she wanted them to figure out, but we acknowledge that this can be useful in other components of a science class such as learning to use new equipment.

$R$ is for reward-Miss Alexander wisely does not try to motivate students by use of the old idea that "if you do X, I will give you Y." Such contingencies are out of fashion today BECAUSE they threaten long-term student commitment, they impede the more powerful intrinsic motivation that drives conceptual growth and often, they don't work as planned. Schwartz, Tsang, and Blair (2016) have offered us a very nice brief "article" on the use of rewards in modern education. (Please note again that each of the 26 chapters is short, and can be seen as an essay argument with evidence on factors that affect learning).

$V$ is for visualization - This section of $\mathrm{ABC}$ s offers strong support for the role that visuals can play in increasing understanding. Whether student generated or student analyzed, visuals help us "see" information, relationships, and connections between ideas. Perhaps the argument can be made that Miss Alexander evokes a piece of this strategy by using the maps to help students interpret information about the Earth's crust, but this strategy did not seem to be a key component of this particular task. In fact, it is likely that students will visualize more deeply when they begin to study the standard map of plate boundaries.

$W$ is for worked examples - Like visuals, worked examples offer alternative models that can be used by novices as they try to gain understanding. Miss Alexander did not give the students a template to follow or sample work by previous students...YET; she is letting them develop their own. Later in their learning they could profit by seeing and examining other examples of work similar to their own (see A and $\mathrm{C}$ above). Please note that follow up lessons would include students using the standard plate boundary map to answer questions and worked examples would be an appropriate strategy to use at this point.

$Z$ is for Zzz's - Finally, the book ends with an essay on the effects of sleep (and sleep deprivation) and its role in the internal codification of new ideas in a person's brain. In short, little sleep means little learning. This is an essay that teachers should know about and talk about with students (especially college students). Healthy sleep may have become the first casualty of these stressful, anxiety ridden adolescent/young adult lives: this trend toward sleep deprivation does not bode well for deep conceptual learning.

\section{Closing}

We posit that teaching, and teachers, need explicit linkages to research, but too often a gap between practice and theory develops. The 2016 book by Schwartz, Tsang, and Blair, and our interpretation, certainly promote an approach that calls for explicit integration of learning research on classroom 
practice. In light of this, we see applications for this article in teacher education programs and in professional development for in-service teachers.

The best teacher education programs show candidates how to link theory with practice so that the candidate's planned activities are engaging and instructive and the candidate knows why they are so. We see our article as a potential learning activity for teacher education candidates. We encourage candidates to analyze this lesson in various ways before reading our insights and therefore have included the time-stamp version of the vignette and the full lesson plan.

Similarly, professional development for in-service teachers must draw an explicit linkage between research and practice. In-service teachers need to discover research in a form that is directly applicable to their own classroom. As such, we hope that our vignette and lesson plan provide a concrete example of many of the strategies esteemed by Schwartz, Tsang, and Blair (2016) for teachers looking to incorporate these strategies into their own lessons.

Finally, we only briefly mentioned the social and emotional learning (SEL) strategies discussed in the ABC's but we feel that that more weight should be given to this topic (Alexander \& Vermette, 2019). We see chapters $B, L, N, P, X$, and $Y$ as pertaining to the integration of social and emotional learning into cognitive lessons, perhaps in the fashion of dual objective lessons (Vermette \& Kline, 2017). With New York State's recent adoption of SEL standards, a more comprehensive method of integration of these strategies is forthcoming from us, as we see the teaching and learning of SEL as an educator's most important pursuit. We furthermore see The ABC's of How We Learn: 6 Scientifically proven approaches, how they work, and when to use them (Schwartz, Tsang, and Blair 2016) as having a clear and vital role in this work.

\section{Declaration of Conflicting Interests}

The author declared no potential conflicts of interest with respect to the research, authorship, and/or publication of this article.

\section{Funding}

The authors received no financial support for this research.

\section{References}

Alexander, K., and Vermette, P.J. (2019). Implementing social and emotional learning standards by intertwining the Habits of Mind with the CASEL competencies. Manuscript submitted for publication.

American Modeling Teacher Association. (2014). Discovering plate boundaries. MSS Gr 7 U 4.3 Act

3: Discovering Plate Boundaries.

Brooks, J.G., \& Brooks M.G. (1993). In search of understanding: The case for constructivist classrooms. Alexandria, Virginia: Association for Supervision and Curriculum Development.

Bruner, J.S. (1956). A study of thinking. The University of California: Wiley.

Buffalo State. (2016). The whiteboarding norms are adapted from a set proposed in the PHY 620 course at Buffalo State University in 2016.

Costa, A.L., \& Kallick, B. (2000). Discovering \& exploring habits of mind. A developmental series, $B \mid$ book 1. Alexandria, VA: Association for Supervision and Curriculum Development.

Duckworth, A. (2016). Grit: The power of passion and perseverance. New York: Scribner. 
Dweck, C. S. (2008). Mindset: The new psychology of success. New York: Balantine Books.

Ericsson, K. A., Krampe, R. T., \& Tesch-Römer, C. (1993). The role of deliberate practice in the acquisition of expert performance. Psychological review, 100(3), 363-406.

http://doi.org/10.1037//0033-295X.100.3.363

Flynn, P., Mesibov, D., Vermette, P. J., \& Smith, R. M. (2004). Applying standards-based constructivism: A two-step guide for motivating middle and high school students. Larchmont, NY: Eye On Education.

Frayer, D. A., Fredrick, W. C., \& Klausmeier, H. J. (1969). A schema for testing the level of concept mastery: report from the Project on Situational Variables and Efficiency of Concept Learning. Wisconsin Research and Development Center for Cognitive Learning.

Glasser, W. (1999). Choice Theory: A new psychology of personal freedom. New York: HarperCollins Publishers.

Goleman, D. (2013). The focused leader. Harvard Business Review, 91(12), 50-60.

Hattie, J., \& Timperley, H. (2007). The power of feedback. Review of Educational Research, 77(1), 81-112. https://doi.org/10.3102/003465430298487

Ladson-Billing, G. (2009). The Dreamkeepers: Successful teachers of African American children. San Francisco: John Wiley and Sons.

Martin, L. (2015). The promise of the maker movement for education. Journal of Pre-College Engineering Education Research (J-PEER), 5(1), 30-39. https://doi.org/10.7771/2157$\underline{9288.1099}$

Schwartz, D. L., Tsang, J.M., and Blair, K.P. (2016). The ABC's of how we learn: 26 scientifically proven approaches, how they work, and when to use them. New York: W.W. Norton.

Vermette, P. J. (2009). Engaging teens in their own learning: 8 Keys to student success. Larchmont, NY: Eye on Education.

Vermette, P.J., and Alexander, K. (2019). Effective questioning techniques in the question-driven classroom. Manuscript in preparation.

Vermette, P.J. and Kline, C. L. (2017). Group work that works: Student collaboration for the $21^{\text {st }}$ century. New York: Routledge. https://doi.org/10.4324/9781315618364 
Appendix A

Local School District Lesson Plan

\begin{tabular}{|c|c|c|c|c|}
\hline Course General Science & \multicolumn{2}{|c|}{$\begin{array}{l}\text { Title: } \\
\text { Discovering } \\
\text { Plate Boundaries }\end{array}$} & $\begin{array}{l}\text { Grade Level: } \\
\text { 7th }\end{array}$ & $\begin{array}{l}\text { Teacher: } \\
\text { Miss Alexander }\end{array}$ \\
\hline Lesson Components & \multicolumn{4}{|c|}{$\begin{array}{l}\text { Essential Question(s) or Objective(s) (It is recommended that lesson objectives are } \\
\text { written in the form of questions and revealed to students at the beginning of } \\
\text { lessons, so they can be used at lesson closure to check for understanding) } \\
\text { 1. How do pieces of the Earth move (and is it only the continents that can move)? } \\
\text { 2. (What and where are the plate boundaries?) This is the underlying question of } \\
\text { the lesson, but I have included it here in parentheses because we are hoping } \\
\text { students will discover this through their inquiry. We do not want to present this } \\
\text { as an opening question, especially because students may not know that plates } \\
\text { even exist at this point in our unit. } \\
\text { 3. How well can I interpret and summarize data? } \\
\text { 4. How well can I listen and share ideas in diverse groups? }\end{array}$} \\
\hline \multicolumn{2}{|c|}{$\begin{array}{l}\text { Student Guiding Question(s) } \\
\text { What questions direct this } \\
\text { lesson and connect to the } \\
\text { essential question? Guiding } \\
\text { questions can be used } \\
\text { throughout the lesson in a } \\
\text { formative manner to support } \\
\text { student understanding for the } \\
\text { lesson and the connection to } \\
\text { the unit and/or course. }\end{array}$} & \multicolumn{3}{|c|}{$\begin{array}{l}\text { This lesson is structured around Question } 1 \text { above as the Guiding Question, but as } \\
\text { noted above the goal is for students to discover and answer Question } 2 \\
\text { throughout the activity. Please note that students are not expected to be able to } \\
\text { fully answer Question } 2 \text { on their own and may not do so by the end of this lesson. } \\
\text { Instead, this lesson is used to introduce the concept of tectonic plates as we move } \\
\text { from Wegener's Theory of Continental Drift to the current Theory of Plate } \\
\text { Tectonics. Question } 3 \text { is the skill component of the lesson, and Question } 4 \\
\text { addresses our affective goals. }\end{array}$} \\
\hline \multicolumn{2}{|c|}{$\begin{array}{l}\text { State Standards/Performance } \\
\text { Indicator(s) What do you } \\
\text { want your students to know } \\
\text { and/or be able to do by the end } \\
\text { of this lesson? }\end{array}$} & \multicolumn{3}{|c|}{$\begin{array}{l}\text { Intermediate Science Standards. } \\
\text { Standard 4. The Physical Setting. Students will understand and apply scientific } \\
\text { concepts, principles, and theories pertaining to the physical setting and living } \\
\text { environment and recognize the historical development of ideas in science. } \\
\text { Key Idea 2: Many of the phenomena that we observer on earth involve } \\
\text { interactions among components of air, water, and land. } \\
\text { Performance Indicator 2.2: Describe volcano and earthquake patterns, the rock } \\
\text { cycle, and weather and climate changes. } \\
\text { Major Understandings: } \\
\text { - 2.2e The Theory of Plate Tectonics explains how the "solid" lithosphere } \\
\text { consists of a series of plates that "float" on the partially molten section of } \\
\text { the mantle. Convection cells within the mantle may be the driving force } \\
\text { for the movement of the plates. } \\
\text { - 2.2f Plates may collide, move apart, or slide past one another. Most } \\
\text { volcanic activity and mountain building occur at the boundaries of these } \\
\text { plates, often resulting in earthquakes. }\end{array}$} \\
\hline
\end{tabular}


NYSSLS:

MS-ESS2-2. Construct an explanation based on evidence for how geoscience processes have changed Earth's surface at varying temporal and spatial scales.

DCI:

- ESS1.C: The History of Planet Earth. Tectonic processes continually generate new ocean sea floor at ridges and destroy old sea floor at trenches.

- ESS2.B: Plate Tectonics and Large-Scale System Interactions. Maps of ancient land and water patterns, based on investigations of rocks and fossils, make clear how Earth's plates have moved great distances, collided, and spread apart.

Science and Engineering Practice \#4: Analyzing and Interpreting Data Crosscutting Concept \#1: Patterns

Assessment Tool(s)

How do you obtain evidence of each student's learning during this lesson?
In this lesson, I will informally, formatively assess students while I circulate during their group work. I will also informally, formatively assess students as they share their findings with their new groups as we complete the jigsaw. If time permits, I plan to ask students to share out their final ideas at the close of class (to see what their thinking is on the final question - which drives at essential questions \#2). If needed, we will do this "share out" at the beginning of the next class. As this is an introductory lesson to a new topic, there are no formal assessments included in this lesson.

Students will be learning about the location (and existence) of plate boundaries. The goal is for students to recognize that volcanoes and earthquakes occur most frequently in the same geographical locations. Students are expected to posit ideas of what the crust is doing at these locations (moving). They are also expected to see that new crust is formed at oceans, and will be challenge to explain how this can happen (and how the earth is not getting any larger). All of these findings are the basis for the introduction of the Theory of Plate Tectonics. In follow-up lessons, students will be learning about the different kinds of plate boundaries. Students will be working on the Science and Engineering Practice of analyzing and interpreting data as they will need to interpret various maps, summarize this data, and then share their findings with other students.

Students will be working on their affective skill of listening and sharing ideas (with empathy and understanding) as they will work in two different groups during this jigsaw lesson.

Learning/Differentiation Opportunities

What are the students doing during this lesson? Depending on where lesson falls in the unit, has teacher identified struggling students who are lacking understandings and is the teacher using re-teach
Because this is an inquiry-based laboratory, we expect all students to struggle slightly with this new information. We will provide guidance as needed, but please note students are not expected to have all the answers at this point (instead we're striving to push them to ask the right questions). While it is atypical for me, I plan to assign groups randomly as I will let students draw career cards that will determine their groups. I am hoping that this element of the lesson will increase motivation. If needed, I will regroup students (based on ability or behavioral issues). 
opportunities and

differentiated instruction to support students who "aren't getting it." Conversely, as teachers identify students who are excelling in the unit, what opportunities have those students been given through differentiated instruction to extend, refine and deepen their knowledge within the unit and course.

\section{Teaching Strategies NOTES:}

What is the teacher doing, and what does the teacher need to remember during this lesson?
Period 3 is an inclusion class with students with diverse needs. Assistance will be given to students who struggle to transfer data from one map to another. In particular, some students will struggle with the different orientations of each map and we will explicitly explain this to them as needed. We will also coach students who are working on their affective skills, requiring them to show respect to their classmates as needed. Students who struggle with motivation will be encouraged as needed and their contributions to group work will be monitored.

Our higher-achieving students are expected to excel at data interpretation in this lesson and we will encourage them to help any struggling group members. Because of this, we will consider this a lab where "no one is done until everyone is done" and will discourage higher students from racing through without consulting their group. This will benefit the higher students by encouraging them to practice their affective skills and will benefit struggling students by rendering them support from their peers.

\section{Opening:}

I will pose the question "Is it just the continents that move on Earth?" as I distribute career cards and explain the inquiry to students.

\section{Exploratory:}

Students will meet with a team of similar scientists at this point (there will likely be two teams of each type of scientist). In these groups, they will analyze their assigned map and answer the questions for their task on the lab sheets.

\section{Discovery:}

Students will now move into new groups of diversescientists to share their different findings. They will work together on questions $7,11,13$ and 14 of the lab sheet.

\section{Closing:}

Time permitting, we will share students' whiteboards and discuss our findings and interpretations as they relate to our Plate Tectonics unit. We will continue this "share out" first thing next class if needed.

\section{Student Reflection} Opportunity/Question

Within the lesson are students given the opportunity to provide feedback to issues related to content, product or process associated with the lesson.

\section{Resources and Materials}

(Describe any technology integration being utilized during the lesson)
I am working to develop a classroom culture where students feel comfortable asking questions and making mistakes. As such I hope that students feel comfortable providing feedback throughout the inquiry. Students will have formal opportunities to provide feedback to me as I circulate through their groups and on their lab sheets. Additionally, we have been periodically completing Google Exit Ticket Checkpoints, which allow students to provide feedback both on their understanding and on the functioning of their groups. While we will not have Checkpoint at the end of this lesson, the topics covered today will be assessed on our next Checkpoint (likely on Friday).

Today's lab will be pen, paper, and whiteboard. Each student will complete their own lab sheet. Groups will also produce a whiteboard for the final share out (which we will complete at the end of today or at the beginning of the next class depending on time). I have been incorporating whiteboarding strategies like this (and those in the Modeling curriculum) into my classroom throughout the year. 